\title{
Problem Of Methane-Air Mixture Explosions In Working Faces Of Coal Mines At Mining Intensi- fication And Ways Of Its Solution
}

\author{
Sergey Novoselov ${ }^{1 *}$, Valeriy Popov ${ }^{2}$, Yuriy Filatov ${ }^{1}$, Hee Lee ${ }^{2}$, and Anatoliy Golik ${ }^{2}$ \\ ${ }^{1}$ International Academy of Ecology and Life Protection Sciences, 194021, 3 Institutsky per., Saint- \\ Petersburg, Russia \\ ${ }^{2}$ JSC «NC VostNII», 650002, 3 Institutskaya Str., Kemerovo, Russia
}

\begin{abstract}
The paper presents the problem of methane explosions prevention in the most hazardous mine section - working face, based on the preventive measures to exclude key factors of methane explosion. The measures of the methane explosions prevention in the working faces during the intensification of coal mining are determined. A method for the aggregated calculation of absolute methane emission in the working face at work of a shearer is proposed. An explosive concentration can occur at any time during cutting coal due to irregularity of methane emission and ventilation processes in the face, which makes the risk of explosion uncontrollable. Consequently, the effective preventive drainage of coal seams is primarily required for the intensification of coal mining. A series of new studies on intensity of methane emission will be required for per face output which is about 30,000 tons per day or more to create new regulatory documents.
\end{abstract}

\section{Introduction}

The problem of methane explosions has existed since people began to extract coal from the coal seams that contain significant volumes of occluded methane. To solve this problem and prevent methane explosions, it is necessary to exclude the joint effect of two risk factors: the presence of explosive methane-air mixture and the source of ignition (striking of a spark, an arc or methane ignition temperature of $650-750^{\circ} \mathrm{C}$ ). These hazard factors occur under the following circumstances:

Methane explodes at volumetric concentration in the air of 4.9 to $15.4 \%$. The most flammable volume fraction (volume concentration) is $8 \%$. Methane reaches maximum explosive force at volume fraction equal to $9.5 \%$.

Explosiveness of methane-air mixtures at atmospheric pressure is determined by the graph shown in Figure 1.

\footnotetext{
*Corresponding author: nowosyolow.sergej@yandex.ru
} 


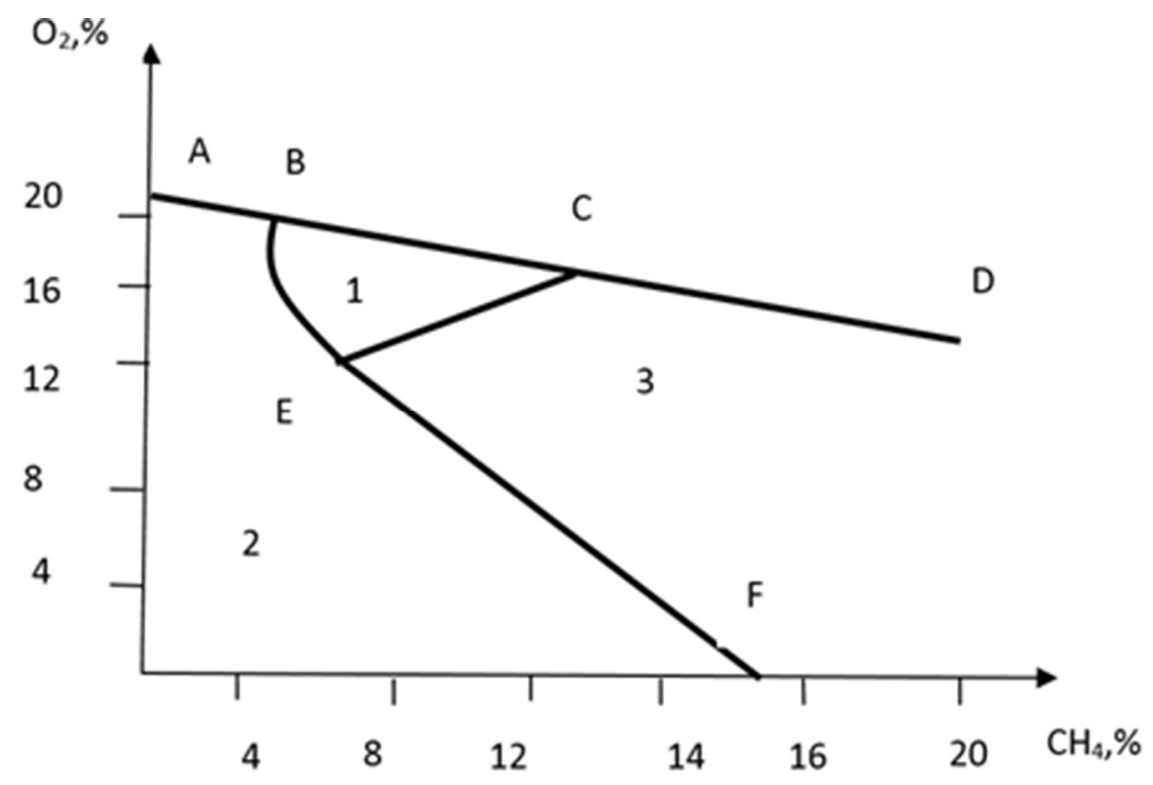

Fig. 1. Explosiveness of methane-air mixtures as a function of concentrations of oxygen and methane in the mine atmosphere, where 1 is explosive mixture; 2 is non-explosive mixture; 3 is mixture that becomes explosive when diluted with oxygen.

Point A characterizes the oxygen content in atmospheric air; points $\mathrm{B}$ and $\mathrm{C}$ are, respectively, the lower and upper limits of the explosiveness (LEL and UEL) of the methane-air mixture. Point E corresponds to the LEL of the mixture against the oxygen content. All points below the AD line characterize flammable and explosive mixtures of methane with the air oxygen. Interval BE corresponds to LEL of the mixture, interval CE to the UEL. Mixtures in area 1 are explosive, in area 2 flammable in the presence of a heat source, in area 3 flammable and explosive when diluted with oxygen. In area above the $\mathrm{AD}$ line, the methane-air mixture cannot be prepared. Triangle $\mathrm{CBE}$ is referred to as the explosiveness triangle for methane-air mixtures. For example, at the methane concentration of $8 \%$ and the oxygen concentration of $16 \%$, the methane-air mixture is explosive, but at the oxygen concentration of $8 \%$, non-explosive.

The increase in temperature leads to reduction in the LEL of the methane-air mixture. At the temperature of $400^{\circ} \mathrm{C}$ this limit is $3 \%$. When the methane-air mixture is saturated with water vapour, the explosive limit is reduced. Carbon dioxide also reduces the UEL. As the dust content of the mine atmosphere increases from 5 to $30 \mathrm{~g} / \mathrm{m}^{3}$, the LEL falls from 3 to $0.5 \%$. At that, the ignition energy of the dust-gas mixture increases by a factor of 100-300, compared to the methane-air mixture.

Methane is found in coal seams and the host rock. When conducting mining operations, methane is released into the workings faces from the developed, undermined and overworked coal seams and the host rock and the mined-out areas. The rate of methane release from the coal seams and rock is determined by the gas content in the strata, pressure and temperature, but also by permeability, porosity, gas release capacity, gas retention capacity of the coal or rock, structure of the coal seam and mining technology.

High gas content in the coal seams increases the risk of methane explosions, depends on their depth, metamorphism intensity, tectonic faults, and association with certain geological structures and can reach 40 to $45 \mathrm{~m}^{3}$ per 1 ton of combustible matter. Russian coal industry, including mining companies, Federal Service of Environmental, Technological and Nuclear Supervision and scientific community, gives paramount 
consideration to the methane explosion risk assessment and explosion safety of coal mines. Relevance of analysis and assessment of the methane explosion risk factors in the mining industry is acknowledged internationally [1-11].

Based on the present-day practices of coal mining operations and content analysis of both domestic and international published works and regulations, it can be said that simultaneous application of three basic actions strategically prevents the methane explosion hazard: (1) preliminary gas drainage from the coal seams, (2) adequate and efficient ventilation systems, and (3) improved automatic gas monitoring system (GMS).

In addition, it is necessary to eliminate the following factors that disturb the mode of ventilation:

- fault trips or performance degradation of the fans,

- operation of the fans in recirculation mode,

- air losses in the ventilation ducts, through air crossings, stoppings, etc.,

- short-circuiting of ventilation air,

- reduction in the actual cross sectional area of mine openings as compared to the designed area (obstructing, rock spalling, etc.).

To eliminate the sources of explosive gas ignition (static electricity sparks; electric arc; flame; smoking; incandescent particles from electric detonators and parts of mechanisms; frictional impact; metal hammering against metal, pyrites or siliceous rocks; spontaneous inflammation), it is required to monitor the conditions in the mine, follow the safety rules and conduct of efficient preventive maintenance of machinery and equipment. Modern coal shearer-loader are equipped with sensors that control position of the working element, motion speed and the position of the coal-cutting machine [9]; thus, the machine operator is able control the intensity of methane emission by changing the feeding speed.

Moreover, a sufficient number of remote monitoring and alarm systems of various levels and purposes have been developed. Such systems perform the following functions:

- monitoring and operation of the mine technological systems and equipment,

- video surveillance of work stations,

- voice and video wireless communications,

- tracking personnel and vehicles, locating trapped miners,

- recording of working hours and time-keeping,

- safety monitoring of the mine atmosphere, maintenance of its gas composition within the standard limits,

- required air distribution among the ventilated facilities, control of ventilation doors and monitoring of their position,

- control of personnel safety near the moving parts of mining machines and mechanisms [10].

Dispatching control of international mining enterprises appears an operative means of productivity enhancement and a decision-making tool for both personnel and management [11].

However, even close consideration of all the above risk factors of methane explosions in coal mines seems insufficient to radically eliminate such accidents at hazardous production facilities unless a comprehensive approach to the problem is introduced and the human factor that contributes into the occurrence emergency situations is taken into account. The influence of human factor can be minimized by:

- proper selection of professional personnel (implementable yet a difficult task),

- systematic safety training and briefing on compliance with the occupational health and safety rules, safety exams for personnel engaged into the in the production process.

\section{Materials and methods}


Recently, two mines of SUEK-Kuzbass JSC - Taldinskaya-Zapadnaya-1 mine and V.D. Yalevsky mine - reached the milestone of monthly coal production from a single working face, equal to $1 \mathrm{mln}$ tons, and in May 2017, V.D. Yalevsky mine established an absolute record of production - $1.407 \mathrm{mln}$ tons per month from a long face. Thus, the rate of stopeface advance was at least $20 \mathrm{~m} /$ day and, accordingly, the technology of coal mining can be determined as intensified.

A number of methods for determining the methane content in strata, where the main parameters are the relative rate of methane release from the coal seam, the time factor and production parameters, including broken-down coal, were analyzed. Such analysis demonstrated that, omitting certain empirical dependencies on gas dynamics, the rate of the absolute methane release $\left(J, \mathrm{~m}^{3} / \mathrm{min}\right)$ into the long-face areas can be calculated by proposed formula 1 .

$$
\mathrm{J}_{\mathrm{I}}=\mathrm{m} \cdot \mathrm{l} \cdot \mathrm{\gamma} \cdot \mathrm{q} \cdot \mathrm{r} \cdot \mathrm{k}
$$

Consider an aggregated calculation based on actual figures if seam thickness $(m)$ is 5 $\mathrm{m}$, maximum feed rate $(l)$ of a modern coal-cutting machine (for example, shearerloader SL-900) is $36 \mathrm{~m} / \mathrm{min}$, relative methane-bearing capacity $(q)$ is 5,10 and $15 \mathrm{~m}^{3} / \mathrm{t}$ for the I, II, III category mines respectively, average specific gravity of coal $(\gamma)$ is 1.34 $\mathrm{t} / \mathrm{m}^{3}$, methane desorption factor $(k)$ is $20 \%$, and operating width of the coal-cutting machine $(r)$ is $1000 \mathrm{~mm}$. If the shearer-loader advances in the working face at the rate of $36 \mathrm{~m} / \mathrm{min}$, the rate of the absolute methane release $(J)$ shall be:

for the I category mines $-\mathrm{J}_{\mathrm{I}}=5 \cdot 36 \cdot 1.34 \cdot 5 \cdot 1 \cdot 0.2=241.2 \mathrm{~m}^{3} / \mathrm{min}$,

for the II category mines $-\mathrm{J}_{\mathrm{II}}=10 \cdot 36 \cdot 1.34 \cdot 5 \cdot 1 \cdot 0.2=482.4 \mathrm{~m}^{3} / \mathrm{min}$,

for the III category mines $-\mathrm{J}_{\mathrm{III}}=15 \cdot 36 \cdot 1.34 \cdot 5 \cdot 1 \cdot 0.2=723.6 \mathrm{~m}^{3} / \mathrm{min}$.

Therefore, to ensure the standard content of the mine atmosphere, it is required to intake $25 \div 75$ thousand $\mathrm{m}^{3}$ of fresh air per minute.

However, at a maximum airflow velocity of $4 \mathrm{~m} / \mathrm{s}$ (according to the OHS rules) and the neat cross-sectional area of about $10 \mathrm{~m}^{2}$, the amount of air flowing through the face area cannot be more than $2,400 \mathrm{~m}^{3} / \mathrm{min}$. Insufficient air intake leads to an increased concentration of methane in the working face atmosphere. It should be taken into account that, according to the $\mathrm{OHS}$ rules, the $\mathrm{CH}_{4}$ concentration in the ventilation airflow coming from the extraction area should be less than $1 \%$, and the GMS sensors are adjusted to the concentration of $1.3 \%$. It should also be noted that, when cutting the coal, the $\mathrm{CH}_{4}$ concentration is even higher under the roof in the zone of the shearer cutting drums.

In such conditions, with the GMS enabled, continuous operation in the long face appears impossible because of regularly occurring emergency power shutdowns due to excessive methane concentrations. That is why the $\mathrm{CH}_{4}$ control sensors are frequently disengaged deliberately, which creates potential hazardous situations.

These calculations are presented as tentative, for they do not take into account the specifics of the gas dynamics, gas release factors, and the coefficients of variation, which can actually alter the resulting figures, because the range of gas dynamics values for the Kuzbass coal seams is significant.

However, these calculations correlate with the results of research conducted by Zakharov, Zaburdyaev and Artemyev in the Kuzbass mines. According to the presented graph, which characterizes the dependence of the methane release rate on the average daily coal output in the Kuzbass mines, the methane release rate $\left(I, \mathrm{~m}^{3} / \mathrm{min}\right)$ reaches 640 $\mathrm{m}^{3} / \mathrm{min}$ at the production rate $(A, \mathrm{t} /$ day) of $30,000 \mathrm{t} /$ day.

Taking into account the above calculations, it can be concluded that in very gassy mines, at the relative methane-bearing capacity of $15 \mathrm{~m}^{3} / \mathrm{t}$ or more and intensification of coal production to $20,000-30000$ t/day per a working face, safety issues related to the 
presence of methane will definitely occur, unless preliminary gas drainage from the coal seams and actions (2) and (3) proposed above are applied.

\section{Conclusion}

The concept of 'methane safety' in the Kuzbass coal mines suggests a comprehensive proactive approach to choosing methane explosion prevention methods. This problem cannot stand a one-legged approach, but must be solved in all its sides simultaneously: explosive methane-air mixtures in the faces are to be avoided; the level of explosion protection of the electrical equipment is to be monitored and improved, and personnel's professional attitude is to be encouraged. All of the above can be ensured by systematic monitoring of activities at the hazardous production facility - a coal mine - using automated means of control.

\section{References}

1. The Precautionary Principle. World Commission on the Ethics of Scientific Knowledge and Technology, 52 (UNESCO, 2005)

2. $\quad$ AS/NZS ISO 31000.. Risk management (2009)

3. CAN-CSA-Q850-97. Risk Management Guidelines for Decision-Makers. National Standard of Canada

4. Coal Mining Safety and Health, (Queensland, Australia, 1999)

5. Coal Mining Safety and Health Regulations, (Queensland, Australia, 2001)

6. G. Nugent, Emergency Mine Entry. Re-entry and Knowledge Management. Queensland andp NSW Mines Rescue Services.

7. The RiO Declaration on Environment and Development. (1992)

8. QCVN 01: 2011/BCT. Quy chuẩn Kỹ thuật Quốc gia về an toàn trong khai thác hầm lò. (Vietnamese, 2011)

9. M. Bekker, P. Martin, Mining Report Glückauf, 4, 10 (2015)

10. M. Bekker, P. Martin, Mining Report Glückauf, 4, 38 (2015)

11. R. Kipp, M. Junker, Mining Report Glückauf, 2, 10 (2014) 
